This item was submitted to Loughborough's Research Repository by the author.

Items in Figshare are protected by copyright, with all rights reserved, unless otherwise indicated.

\title{
Authority signaling: How relational interactions between journalists and politicians create primary definers in U.K. broadcast news
}

PLEASE CITE THE PUBLISHED VERSION

https://doi.org/10.1177/1464884918762848

\section{PUBLISHER}

(C) The authors. Published by SAGE Publications Ltd

\section{VERSION}

AM (Accepted Manuscript)

\section{PUBLISHER STATEMENT}

This work is made available according to the conditions of the Creative Commons Attribution-NonCommercialNoDerivatives 4.0 International (CC BY-NC-ND 4.0) licence. Full details of this licence are available at: https://creativecommons.org/licenses/by-nc-nd/4.0/

\section{LICENCE}

CC BY-NC-ND 4.0

\section{REPOSITORY RECORD}

Chadwick, Andrew, Declan McDowell-Naylor, Amy P. Smith, and Ellen Watts. 2019. "Authority Signaling: How Relational Interactions Between Journalists and Politicians Create Primary Definers in U.K. Broadcast News". figshare. https://hdl.handle.net/2134/28487. 


\section{Authority Signaling: How Relational Interactions between Journalists and Politicians Create Primary Definers in U.K. Broadcast News}

Andrew Chadwick, Declan McDowell-Naylor, Amy P. Smith, \& Ellen Watts

Andrew Chadwick is Professor of Political Communication in the Centre for Research in Communication and Culture and the Department of Social Sciences at Loughborough University.

Email: a.chadwick@lboro.ac.uk

Declan McDowell-Naylor, Amy P. Smith, and Ellen Watts are doctoral researchers and research assistants in the New Political Communication Unit at Royal Holloway, University of London. Email: Declan.Mcdowell-Naylor.2013@live.rhul.ac.uk; Amy.Smith.2011@live.rhul.ac.uk;

Ellen.Watts.2012@live.rhul.ac.uk

This research was funded by a grant to Andrew Chadwick from the British Academy and the Leverhulme Trust (\#SG151065); he thanks their generous support.

Forthcoming in Journalism.

Authors' accepted manuscript. Please read the final, typeset version of this article when it is published at http://journals.sagepub.com/home/jou 


\begin{abstract}
How journalists construct the authority of their sources is an essential part of how news comes to have power in politics and how political actors legitimize their roles to publics. Focusing on economic policy reporting and a dataset of 133 hours of mainstream broadcast news from the five-week 2015 U.K. general election campaign, we theorize and empirically illustrate how the construction of expert source authority works. To build our theory we integrate four strands of thought: an important, though in recent years neglected, tradition in the sociology of news concerned with "primary definers"; the underdeveloped literature on expert think tanks and media; recent work in journalism studies advocating a relational approach to authority; and elements from the discursive psychology approach to the construction of facticity in interactive settings. Our central contribution is a new perspective on source authority: the identification of behaviors that are key to how the interactions between journalists and elite political actors actively construct the elevated authoritative status of expert sources. We call these behaviors authority signaling. We show how authority signaling works to legitimize the power of the U.K.'s most important policy think tank and discuss the implications of this process.
\end{abstract}

\title{
Keywords
}

Journalism, sources, authority signaling, primary definers, discourse, power, legitimacy, broadcast news 
The consequences of how journalists use sources is an enduring object of communication research. From work on the sociology of journalism in the 1970s and 1980s to the turn toward "indexing" and "framing" in the 1990s, through to recent analyses of how digital media are reshaping power in news making, the question of who has voice and authority in mediated constructions of reality remains central to how we interrogate journalism's claim to represent the world (see for example Bennett, 1990; Carlson, 2017; Franklin \& Carlson, 2010; Gans, 1979; Tuchman, 1978; Zelizer, 1990).

How journalists construct the authority of their sources is an essential part of how news comes to have power in politics and how political actors legitimize their roles to the public. When power is legitimized, it becomes authority, which in turn leads to action that makes a difference. Key here is how the authority of sources is maintained by the kind of interactive work among journalists and sources that news logics demand. This matters for all areas of journalism but is particularly important for policy news. In this field, patterned inequalities in the representation of sources may, over time, serve to narrow public debate and privilege some perspectives over others. We therefore begin from the normative principle that when journalists source they ought to give public voice to a diverse range of policy perspectives. And policy news in particular should empower citizens to understand and choose from among a wide range of possible alternatives.

In this study we theorize and empirically illustrate how the construction of source authority works. We do so by focusing on an area of news that has grown increasingly important in the aftermath of the global financial crisis of the last decade: economic policy reporting. Our central contribution is a new perspective on source authority, namely the identification of behaviors we suggest are key to how the interactions between journalists and elite political actors actively construct the elevated authoritative status of expert sources. We call these behaviors authority signaling. 
We analyzed a sample of 169 programs (133 hours) of mainstream broadcast news during the five-week 2015 U.K. general election campaign. Our sample (see Table 1) consisted of the main mass-audience evening news bulletins on the U.K's five most-watched television channels, together with BBC Radio 4's mass-audience morning news show, Today. We show how authority signaling among elite journalists and political actors worked to legitimize and enhance the power of what has become the U.K.'s most important nongovernmental policy organization — the Institute for Fiscal Studies (IFS).

Founded in 1969 by four City of London financiers, today the IFS is an independent, nonpartisan think tank of 40 full-time economists. It specializes in accessible but narrowlydrawn analyses of taxation and spending policy, which perennially dominate the news cycle following government budget announcements and party election manifesto launches. Just as importantly, however, with its focus on "deficit reduction" defined as "balancing the books," and its constant use of the national-economy-as-household-budget metaphor-widely criticized by Keynesian economists such as Joseph Stiglitz- the IFS has played a significant role in legitimizing the idea that austerity was an unavoidable policy response to the crisis (Anstead \& Chadwick, 2018: 248-249).

The IFS is also the epitome of a media-savvy expert source. In a study of ideological balance in the use of think tanks in 30,000 BBC news and current affairs programs from 2009 and 2015, Lewis and Cushion (2017: 11-12) showed that the IFS was overwhelmingly the most prominent think tank. In fact, its dominance is extraordinary: in 2009 it made up 47 percent of all references to think tanks in BBC news programmes and was mentioned eight times as often as the second-ranked think tank; by 2015 this had reached 54 percent/five times. But how does the IFS achieve and maintain that status? And what can this tell us about the construction of source authority more generally? 
Our study is divided into two main parts. We begin with our theory of authority signaling. Here we integrate four strands of thought that have hitherto remained separate: an important, though in recent years neglected tradition in the sociology of news concerned with "primary definers"; the relatively underdeveloped literature on expert think tanks and media; recent work in journalism studies that advocates a relational approach to authority; and finally, elements from the discursive psychology approach to the construction of facticity in interactive settings. In the second part of the article, we show how authority signaling works in practice, drawing upon our content analysis of mass-audience broadcast television and radio news from the 2015 election.

\section{Sources and Primary Definers}

The starting point for our theory of authority signaling is Stuart Hall and colleagues' classic work on "primary definers," which emerged in their influential 1978 study of the social construction of news (Hall, et al., 1978: 53-77). Hall et al. argued that elite media reproduce social consensus, not because they are inherently biased, but because they routinely work in relations of reciprocal interdependence with institutional elites. In opposition to instrumentalist accounts that focus on direct political interference by editors and proprietors, Hall et al. (1978: 57) argued that media organizations tend to gravitate toward "regular and reliable institutional sources." Key here is that professional journalists obtain and present statements from those who operate outside the journalism field. Not only does such information enhance the credibility of journalists' stories, it also serves to legitimize journalism's role as provider of “objective” coverage of contentious issues.

Non-governmental expert sources like think tanks, whose status is based on specialist knowledge of policy, are important, though often neglected, candidates for primary definer status. In the U.K. and other media systems with strong public service traditions, expert 
primary definers are particularly significant for enabling professional media organizations to maintain public service impartiality norms. They provide journalists with valuable opportunities to comment on sectional partisan conflicts by promoting "independent" and "authoritative" judgments on public policy and the behavior of political elites. Experts allow journalists to invoke information and opinion that is "external" to partisan conflict and to act in the political field while remaining insulated from accusations of partisan capture or bias. These are important resources for maintaining a news organization's credibility, not least because professional journalists have long been ambivalent about their own expertise. Gans (1979: 129), for example, found that journalists were wary of crossing the boundary between a "generalist" journalistic culture and the culture of specialized, scientific knowledge. Ekström (2002), Schudson and Anderson (2009: 99), and Reich (2012) have all drawn attention to journalism's dual institutional role as chronicler of public events and relatively passive assembler of perspectives supplied by others.

In the U.K. several recent trends in the coverage of election campaigns further strengthen expert think tanks' power as sources. Cushion (2015) has documented the rise of journalistic interventionism and "interpretive news" while Cushion and Thomas (2017) have shown that news values-based, qualitative, editorial judgments about how to cover campaigns are becoming more important than quantitative, stopwatch-measured approaches. Meanwhile, a study by Cushion et al. (2016) revealed that newspaper sources are important influences on broadcast news agendas but the $\mathrm{BBC}$ is least likely to follow the papers' agendas. We suggest that think tanks benefit from these developments because editors and journalists are more likely to invoke expert sources in addition to their own experience and knowledge when they intervene in campaigns to hold politicians to account. And at the BBC in particular, editors and journalists are attracted to think tanks because they help avoid over-dependence on 
newspaper agendas. Thus, while many professional journalists might be ambivalent about becoming experts, they certainly rely upon them in assembling news.

Think tanks are equally useful to political elites, who seek credible support for their policies from outside the partisan field (Schlesinger, 2009). Evidence from think tanks is often mobilized by politicians eager to present "objective" evidence for their chosen policy preferences. For politicians, mobilizing experts to preempt journalists' criticisms is preferable to directly confronting journalists because open conflict might harm reciprocal relationships. Thus, like journalists, politicians who make media appearances have strong incentives to signal the authority of experts.

We suggest that the expert organizations that are routinely invoked in these interactions are likely to have their authority enhanced as part of the process. While this relates to a more general and well-known perspective that there is resource exchange among journalists and politicians, we want to draw attention to the often-overlooked role of institutionalized expert knowledge as a fundamental intermediary in this process. To adapt Davis' terminology (2009), we see expert sources as an important part of the "mediated reflexivity" that now characterizes interactions in the "dance" among political actors and mainstream journalists. As we will show, experts can provide the all-important music that enables the dance. Professional journalists need political elites and political elites need professional journalists; both need expert sources. In the long run, media organizations and politicians may become structurally subordinate to these kinds of sources, to the detriment of source diversity, and this is the essence of Hall et al.'s original theory of primary definers.

\section{Think Tanks as Expert Sources}

There is convincing evidence that expert sources have generally become much more prominent in news over recent years (Albæk, 2011). The think tank field has evolved, as the 
discourse of scientific objectivity and "pure" research that animated the mid-twentieth century emergence of expert policy organizations has partly been displaced by the discourse of the "marketplace of ideas," in which competitiveness, promotion, and political advocacy are more central (Rich and Weaver, 2000).

With few exceptions (Anstead and Chadwick, 2018; Lewis and Cushion, 2017) little systematic research exists on how U.K. think tanks interact with media, despite the fact that these are not simply lone individuals but reasonably well-resourced bodies, and, moreover, bodies that do not possess the same status as academics and universities. Some studies make passing mentions of the importance of agenda-setting but little attempt has been made to explain the mechanisms through which this typically occurs (Cockett, 1995; Stone, 1996).

In their work on think tanks and coverage in six U.S. newspapers, Rich and Weaver (2000) were concerned with the relationships between think tanks" "media visibility" and their organizational, geographical, and financial characteristics. We think it important to explain the deeper origins of "media visibility." We should examine the discursive work that must be performed by journalists, politicians, and experts themselves if an expert's authority is to be legitimized. We therefore focus on how expert authority comes to be constructed through a set of discursive moves we term authority signaling. An expert organization's resources for acting powerfully are partly endogenous to the mediated contexts within which they are presented. How experts are constructed by media in the first place plays a role in maintaining the power that experts need to act in the political field. Expert sources come to be experts not simply because they possess authority that is intrinsically "theirs" but because, through relational interactions, they are discursively constructed as authoritative and independent.

\section{Authority as Relational and Discursively Performed}


Making sense of this process entails identifying patterns in the language journalists and politicians use to describe sources. When editorial decisions are made that lead some sources to be routinely described in favorable ways, this is likely to shape how publics come to interpret the structure of debate — who has authority and who lacks it; who deserves blame and who escapes it (Downey and Toynbee, 2016).

As Carlson argues, "authority is the central element that makes journalism work," not least because "audiences expect journalists to know and to communicate their knowing" (2017: 5, 7). We can add to this Edelman's (1988: 20) useful definition of authority: "willingness to suspend one's own critical judgment in favor of someone regarded as able to cope creates authority." The suspension of critical judgement in favor of expertise is the key force here, and it is crucial for understanding how and why certain institutions seem to escape critical media scrutiny while others are required to continually defend their positions. Yet authority cannot be taken for granted; it must be actively constructed and is best seen, not as an intrinsic property that inheres in individuals and organizations but "relationally... as an understanding formed through the interactions among all the actors necessary for journalism to exist" (Carlson, 2017: 7). Experts may possess a resource (knowledge) that is unevenly distributed throughout society, but they still need to perform their expertise discursively. And think tanks in particular must work in settings that provide access to professional media, who have the resources to enable that performance. In turn, the performance of professional media and journalists depends upon the presence of experts. Mediated interactions are thus generative of political authority. Political authority is not a "thing" that exists anterior to media. It is, to borrow Herbst's term (2003: 489), “media-derived" and requires public maintenance, though the extent of this process can vary in its breadth and depth. 
Sometimes, simple labeling is all it takes. Key adjectives such as "independent," "impartial," "non-partisan" or "respected" can perform a great deal of work in the everyday construction of an expert as sitting outside the partisan and journalistic fields. At other times, in the intensively scripted and highly stylized environment of broadcast news (Craig, 2016; Ekström, 2002), where templates strongly shape reporting and every word and every edit count, a simple, unadorned description of an expert's views may also do the work. In their analysis of the use of statistics in U.K. broadcast news, Cushion, Lewis, and Callaghan (2016: 9) found that 23.5 percent of statistical claims were vague and used in passing without evidence, while 41.3 percent lacked context, analysis or discussion. In broadcast political reporting, vague mentions of this kind are particularly likely to be powerful in constructing authority, especially if there is no juxtaposition of an actor's views with others' views in the same segment or if other actors are treated with contrasting skepticism. Here, it is the simple presentation, without qualifying words or phrases, that comes to perform the discursive work that conveys authority. In contexts like policy news, when there is always scope for contestation, and when other voices are not juxtaposed, verbs like "said," "says," "is" are not unproblematically neutral.

After all, authority also depends on what Latour and Woolgar, in their analysis of the discourses of scientific empiricism, identified as the hierarchy of "modalities" (1986: 77-88, 176-177). This concept captures how qualifying phrases serve to enhance or diminish the authority of what might, at first glance, appear to be simple factual statements. Modalities are used by speakers to signal the tentative nature of a fact. For example, a speaker might say "I think that...," "it is possible that..." "it has been said..." that X is the case. These are statements loaded with relatively strong modalities that qualify the facticity of the account being presented. They are means by which a speaker may signal factual "weight" and, by association, the authority of the speaker making the statement. In contrast, at the top of the 
evidentiary hierarchy are statements with weaker modalities, such as " $\mathrm{X}$ is the case." The most prized statements in scientific discourse are those without modalities, where a fact can simply be presupposed and does not require adornment: it is something that is simply "out there," beyond disagreement. The formulation here (simply " $\mathrm{X}$ ") serves as the strongest expression of the authority of the fact and, by extension, the speaker stating the fact in that moment. In broadcast news, a medium of few words, the simple statement of an actor's views without modalities can be a powerful means of constructing an actor's authority.

Concepts from the field of discursive psychology are also instructive for understanding the language that elevates experts' authority. Potter's (1996) analyses of news discourse suggested that journalist-source interactions typically feature two specific strategies: "interest management" and "category entitlement." Interest management refers to how speakers that have an interest in events being reported in a specific way must actively "work up" their own authority, and, by extension, the authority of their selected sources, by avoiding revealing their own self-interest. Category entitlement refers to how categories are used to establish a speaker's "right" to know something. Drawing upon Goffman's (1981) concept of "footing," Potter (1996: 15) argues that in news interviews speakers use linguistic devices to separate factual descriptions "from their own interests and produce them as neutral and external," for example by referring to some notional consensus away from the immediate interaction or by relying on the category entitlements of specific sources that are presupposed to be qualified to speak. These must be individuals, groups or organizations that can lay some claim to knowledge that is separate from the interests of the speakers involved in the immediate interaction (Potter, 1996: 125). Speakers can also "inoculate" themselves against being presented as having interests that affect what they say. For example, they can present "vague or formulaic descriptions" (Potter, 1996: 118) sufficient to pre-empt the criticism that 
a speaker lacks authority or has a selfish interest in the account being presented in a certain way.

We want to suggest that in broadcast news journalism these discursive strategies converge and result in the authority signaling of expert sources. We should expect, for example, that a political party representative will be presented as having interests that discount her ability to speak objectively. An independent expert, on the other hand, is likely to be presented by a journalist as not having a particular interest and as having a category entitlement to speak on a policy issue. We should expect an expert source's role in the interaction to be enhanced by language that conveys category entitlement, through words such as "independent" or "respected" or language that is not loaded with modalities, such as a bare description of the expert's views or opinions as something that is accepted and "common sense." At the same time, we might expect these descriptions to be repetitive and formulaic, almost casually inserted rather than elaborated upon, because elaboration invites other interview participants and, of course, audiences to pick over the details and find inconsistencies.

\section{Research Design and Method}

The 2015 UK general election campaign ran from March 30 to May 6. We undertook quantitative and qualitative analysis of all of the UK's most popular broadcast news programs during this five-week period. We analyzed 169 programs, which amounted to 133.2 hours of coverage (see Table 1). ${ }^{1}$

-Table 1 here -

Our sampled programs are longstanding staples of political coverage from the main UK broadcasters. We wanted to capture the semantic contexts within which the IFS was presented, hence our decision to focus on the program segment as the unit of analysis. The segment has become an intuitive and instantly recognizable means by which editors divide up 
content, manage their sources, and present evidentiary hierarchies, in a four-stage temporal process Hartley (1982: 118-119) defined as framing, focusing, realizing, and closing. As we define them in this study, segments can be either reports, interviews, or studio discussions. Segments begin with an opening statement from an interviewer or news anchor (framing) and then proceed through an interview or a discussion, or, in the case of a report, a series of video or graphics sequences and to-camera speech from reporters in the field or the studio interacting with sources (focusing and realizing). A segment closes when an interviewer or a news anchor wraps up with a short utterance, before moving on to the next segment. When it makes sense to refer to multiple instances of authority signaling within segments we do so (for example see Figure 2).

Using the entire dataset of programs, we identified and catalogued all program segments in which the IFS featured. A total of 46 program segments -4.67 hours $(3.5$ percent) — of coverage featured IFS personnel or opinion. These 46 segments formed the basis of our close analysis. Next, we developed a pilot coding frame. We broke authority signaling behavior down into three basic types: overt, assumed, and contested. Overt authority signaling refers to language that clearly and overtly gave the impression that the IFS was authoritative, for example, when the organization was described as "independent" or "respected" through "footing" and the building of its category entitlement to speak. Second, and equally important for our theory, assumed authority signaling captures language that presented the IFS's information, opinion or status as if they were simply "the facts" or "common sense" and beyond critique; in other words, where qualifying modalities were weak or entirely absent. The third category we developed was contested authority signaling, which refers to language that conveyed disagreement with the IFS's information, opinion or status. We also wanted to identify the roles played by different actors in each segment, so we coded for when a news anchor, a reporter, or a political party representative signaled the IFS's 
authority. Finally, we also distinguished between direct appearances by party representatives and when journalists reported a party's views.

We tested the coding frame by having three members of the author team code a random sample of 14 news segments. After reviewing inter-coder reliability we removed variables with low reliability, simplified the coding frame, and underwent further discussion and coder training led by the lead author. We ran a second pilot on a different subsample of fifteen program segments to establish reliability for two new variables. Reliability (Krippendorff's alpha) reached very good to excellent for all variables used in this article. ${ }^{2}$ Once the content analysis was completed we undertook detailed qualitative analysis of the episodes to reveal authority signaling at work.

We acknowledge that there are limits to generalizing from a single case. However, a rich account of a single case can be useful for generating theory that might shape future empirical inquiry, and can introduce variables that might have been missed by previous research.

\section{Authority Signaling in Action: Analysis and Findings}

We find significant evidence of authority signaling in the language of journalists and politicians, with examples ranging across the three types of signaling for which we coded. When describing the IFS, journalists in particular made significant use of category entitlement statements and statements with very weak or no modalities. This, coupled with their low levels of contestation of the IFS's information and opinion, supports our theory that journalists played a key role in constructing the IFS's authority. We also find that politicians enhanced the IFS's authority, but in ways that were less straightforward, as we discuss in the following. We begin with some broad quantitative patterns. 
When news anchors signaled the authority of the IFS, they overwhelmingly constructed the think tank as authoritative (see Figure 1). Given the privileged role of anchors in framing news segments (Hartley, 1982: 119), this is a significant finding. Contestation of the IFS's authority was also very rare among reporters, featuring in only two (4.3\%) segments. Overt authority signaling was also frequent: news anchors used language that overtly constructed the IFS as authoritative in $10(21.7 \%)$ segments; reporters did so in 9 $(19.6 \%)$ segments.

However, journalists most frequently signaled the IFS's assumed authority. The think tank's opinions were presented as commonly accepted with seemingly no need for the journalist to explain the organization's authority or justify their use of it as an expert source. Anchors constructed the IFS as possessing assumed authority in 20 (43.5\%) segments, while reporters did so in $14(30.4 \%)$ segments.

As we expected, journalists were not the only actors involved in this process. Twentyfive of our 46 segments (54.3\%) featured authority signaling by at least one non-journalistic organization. Political party sources accounted for the large majority of these, with 28 of 30 separate instances of organizational authority signaling in those 25 segments (see Figure 2). This most frequently occurred when representatives of these parties appeared on the programs, though our research design also captured when reporters relayed parties' views. - Figure 2 here -

As Figure 2 reveals, politicians were more likely than journalists to contest the IFS's authority and less likely than journalists to engage in overt authority signaling. That being said, the modal behavior among political sources was assumed authority signaling. As we discuss below, while the level of contestation varied between parties, throughout the news coverage politicians tended to use the IFS as a prop for their own perspectives, as we predicted. 
We now analyze this and other facets of the discursive and relational construction of the IFS's authority in a more granular way.

\section{Assumed Authority Signaling}

Assumed authority signaling is the dominant discursive form in the construction of the IFS as a primary definer in broadcast news. It is characterized by statements with few or no modalities - there are no attempts to explain the organization's authority nor justify its use as an expert source on economic policy. Instead, IFS interventions are regularly described without qualification, using simple verbs such as "said," and "says."

We identified five key uses of assumed authority signaling. First, journalists sought to hold politicians to account by presenting the IFS, in contrast to politicians, as an informative or revealing source. Second, journalists used distinct metaphors to construct the IFS as possessing the authority to judge parties' performances. Third, politicians benefited from the construction of the IFS as an external, impartial authority because they used the think tank to validate their policy claims. Fourth, we found almost no room for debate over the validity of IFS findings: "belief" in what the IFS said was constructed as an essential requirement for rational engagement in economic policy debate. Finally, journalists took a rather vague and formulaic approach: the IFS was a constant in economic reporting, forming a key part of the logic upon which journalists relied to create recognizable broadcast segments on economic policy during the election.

Journalists used assumed authority signaling to mobilize opinion that was external to partisan conflict. Consider the following segment, in which Labour Party leader Ed Miliband has just raised his economic policy in an interview with Matt Barbet on 5 News Tonight:

Ed Miliband: [...] that is the plan we offer for people in Scotland and indeed, across the United Kingdom. 
Matt Barbet: A plan that is short on detail. You talk about the mansion tax, bringing in enough to save the NHS. It will fall way short. You talk about a 50\% tax rate, that will fall way short, according to the likes of the Institute for Fiscal Studies. How are you going to pay for all this? ${ }^{3}$

This segment was initially framed as a chance to "put the party leaders on the spot" and the IFS was used to hold Miliband's claims to account. It was presented in Barbet's focusing with weak modalities as part of a strategy to evaluate Miliband's economic plan. The use of the simple adverb "according" presents the IFS's claims unproblematically, while the modal auxiliary verb "will," used twice, conveys the certainty of the IFS's claims. Barbet used IFS figures in a similar way when focusing during an interview with Liberal Democrat leader Nick Clegg. Here, Clegg had just finished a description of the Liberal Democrats' economic policy:

Matt Barbet: You say that, but what is lacking, glaringly, is the detail.

Nick Clegg: Not at all.

Matt Barbet: Today we've had a report from the Institute of Fiscal Studies, if you have a listen to this, warning that all the major parties, you included, that you have not provided anything like the full details on plans to cut the deficit. How can people properly decide if none of the parties, yours included, are being clear enough?

Nick Clegg: I don't think you are being entirely fair to your viewers. Actually, the IFS said the Liberal Democrats deserve what they call a small tick. They said we are the most transparent of the parties.

Matt Barbet: They said you are the best of a bad bunch. Which is what they said.

Nick Clegg: There are certain things by the way, where you simply cannot cross the Ts and dot the Is before you come into government. We have gone considerably further and, as the IFS confirmed, as you know, we've always said we would balance the books, which is what Labour won't do, but we will do it more fairly than the Conservatives. ${ }^{4}$

Similarly to Miliband, Clegg did not challenge the IFS's authority. He disputed the accuracy of Barbet's rendering of the IFS's report but not the IFS itself ("as the IFS confirmed"), signaling the IFS's assumed authority in the process.

Constructions of the IFS's assumed authority were present across all the news programs we analyzed. The Today program, for example, avoided using modalities and they 
mobilized the organization frequently when challenging politicians on economic policy. In an interview with Conservative Theresa May, presenter John Humphrys engaged in realizing by doubting the Conservatives' portrayal of Labour's fiscal policy, citing the IFS's opinion: “you’ve told us they’re (Labour) going to put up taxes by $£ 3000$, the Institute for Fiscal Studies rubbished that immediately. 'Misleading,' they said." "Humphrys did not expand on why it was misleading; the IFS said it was misleading, and so it was. Humphrys was not merely questioning May's policy but placing seemingly irrefutable facts before her. Later in the interview, as it moved toward closure, this move was reinforced through Humphrys' surprise at May's support for her party's statistics in the face of the evidence from the IFS that he had just established: "It really surprises me slightly that you're sticking with that $£ 3000$ figure.”

For journalists, this kind of approach serves a dual purpose: it enables them to challenge politicians while appearing as the neutral curators of the information of others rather than experts in their own right. Not only does this enhance the credibility of journalists' narratives, it legitimizes their role as providers of credible, impartial coverage.

Assumed authority signaling was also at work in the metaphors used to suggest that the IFS possessed the power to adjudicate on fiscal policy. Channel 4 News reporter Gary Gibbon used the metaphor of the courtroom, relying on the IFS and its director Paul Johnson to provide authoritative "judgment." The report opened with Gibbon's framing and focusing that the IFS had "judged that even in the first day of the campaign, standards of openness and accuracy were slipping.” A pre-recorded interview with Johnson was then used to realize this, as Johnson was asked to give “marks out of ten for candor." Johnson's judgement that "we haven't got a lot out of ten on either side" was then left hanging, with no further consideration, before the report moved onto a different subject. Similarly, in a 5 News Tonight segment the IFS was described as having "given a tick" to the Liberal Democrats, 
constructing the IFS as though it were an accredited authority providing "official" assessments. These examples, which lacked modalities and depended on vagueness for their effects, enhanced the status of the IFS.

This was made doubly clear through the ways in which the IFS's "godlike" role was manifested in declarations of faith through repeated invocations of "belief" in the IFS's statements. In his Today interview with Theresa May, Humphrys attempted to close with a final challenge: "Well, do you not believe what the IFS said then?" The phrase "do you not believe" is different from asking May if she disagrees with the IFS; assumed authority signaling renders disagreement unavailable. May was left with only one option - to challenge the IFS on the basis of a lack of faith. However to do so would have involved challenging what the journalist has already established as the expert source, so she avoided contesting the IFS in her response and quickly moved the interview on.

Finally, a key feature of assumed authority signaling was the repetitive and formulaic deployment of IFS opinion. Modality-free descriptions of the IFS and its reports were strategically inserted by journalists when politicians discussed economic policy. Stylized encounters resulted, indicating that the pressure of news production leads to the repetitive inclusion of reliable institutional sources. Examples from $B B C$ News at Ten provide evidence of this. On two separate occasions, the BBC's Economics Editor Robert Peston was framed by his anchor as assessing party policy in closer detail. The format used on both occasions was identical: after summarizing the story, Peston realized it by referring to an IFS statement, and then cutting to an IFS representative to reinforce his line. ${ }^{7}$ In another segment led by Peston, the IFS was mentioned thirteen times in less than seven minutes. ${ }^{8}$ This usage became almost mundane, especially if we consider Peston's repetitious use of the simple lowmodality phrase, "the IFS says...." Politicians also responded by using this same tactic, creating a shorthand form of facticity that worked to transcend their own self-interest. 
Overt Authority Signaling

Overt authority signaling relied on the repeated use of footing and category entitlements and a limited range of adjectives such as "independent" (which appeared in 14 segments), “expert" (5 segments), or "respected" (4 segments). Other terms included "clever," "excellent," "impartial," "important," "official," and "sensible," which featured in one segment each.

This extract from ITV News at Ten features some of the most explicit examples of overt authority signaling.

Mary Nightingale (anchor, framing): The number-crunchers at The Institute for Fiscal Studies say there are genuine differences in the spending plans of the main political parties. But the IFS thinks voters are being left in the dark about exactly what those plans are. Our deputy political editor, Chris Ship, has been looking at the findings.

Chris Ship (reporter, focusing): You may not have read through these four party manifestoes and costed their plans but you will be pleased to hear some very clever and very independent people have shone a spotlight on each. And their verdict is: they are all leaving the electorate somewhat in in the dark. ${ }^{9}$

The use of "number-crunchers," "very clever," and "very independent" demonstrates the use of footing and category entitlements to boost the authority of the IFS. The adverb "very" adds emphasis but so too does Chris Ship's gentle admission that it was not he who had undertaken the analysis of the party manifestos but a "clever and independent" external organization.

Similarly, when focusing a BBC News at Ten report on a Labour Party claim that full fiscal autonomy for Scotland (a key part of the Scottish National Party (SNP) argument for Scottish independence) would lead to a "spending hole" Peston referred to information from what he described as the "respected" IFS. Despite referring to the claim as originating from 
Labour, neither he nor the anchor referred back to Labour in the remainder of the segment. Instead, the IFS's analysis was used to explain the spending hole. Labour's authority in making the claim was completely overtaken by the authority of the IFS, to the point where the segment became a report of the IFS's assessment of Labour as much as it was of the SNP's policies.

This use of the IFS's information to realize a news story that was ostensibly about claims made by a political party is an extreme form of journalistic distancing. Rather than rely on the party to provide information, which might require a reporter to present opinions from other parties as a means of showing impartiality, reporting from an IFS standpoint allows journalists to engage in footing to retain their impartiality and authority. The downside is that this kind of practice risks creating unbalanced reporting, as all IFS information is portrayed as accurate while opposing viewpoints from other expert sources and parties themselves are neglected.

An interview with former Conservative Party chairman Grant Shapps for Newsnight also demonstrated how interest management enhanced the status of the IFS, with BBC journalists in particular using category entitlements as a resource to criticize politicians "from a distance." ${ }^{10}$ Realizing using IFS statistics and continually referring to the think tank's independence, anchor Evan Davis strongly and repeatedly criticized Shapps. Davis expressed complete disbelief in Shapps' statements and implied that Shapps was an unreliable source due to his partisan interest in the argument. But by constructing the IFS as an independent authority entitled to speak on economic issues, Davis was able to frame this as the IFS's “disbelief" rather than his own or the BBC's. Davis challenged Shapps: "who do you think the public should believe? Do you think they should believe you, or do you think they should believe the independent fiscal experts of the Institute for Fiscal Studies?" Such favorable 
treatment is a precious resource for any policy actor that seeks to become a regular and trusted source.

When the authority of the IFS was signaled by both politicians and journalists, but for different ends, the central role of the think tank in U.K. economic news was thrown into stark relief. In an interview on the Today program both presenter Jim Naughtie and SNP spokesperson Derek Mackay invoked the IFS to support their arguments. ${ }^{11}$ Naughtie used category entitlement to refer to the organization as "independent" and then stated that as a result of the IFS's analysis "there is absolutely no doubt that if you had full fiscal autonomy in the sense that Nicola Sturgeon means it, what you'd have to do in the Scottish Government is find an extra $£ 7-8$ billion, or find cuts." He repeatedly referred to the IFS's figures throughout this exchange and challenged Mackay's argument that the SNP would not be forced into spending cuts. But rather than denounce the IFS's figures, Mackay dodged the question before trying to use the same IFS report to lend authority to a different SNP policy. He then stated: "I'm not challenging the work that the IFS have done because the report also points out that...," at which point he was cut off by Naughtie, who insisted that because Mackay accepted one aspect of the report he must, by logical extension, accept another: "Well you have to accept the $£ 7$ billion in cuts then."

As we have argued, the IFS becomes an expert source because, through it, both politicians and journalists can make their cases. It allows them to disagree without ultimately damaging their reciprocal relationships. In the interdependence that exists between journalists and politicians, where control passes back and forth between actors, externalizing the source of authority can be an important tool to manage disagreements and delineate roles.

\section{Contested Authority Signaling}


As Figure 2 showed, politicians were far more likely than journalists to signal contestation of the IFS's authority. We end by discussing some examples of this and we show why, in the final analysis, it does little damage to the IFS's status as an expert source.

A close examination of the interactions revealed that contestation occurred when a politician was responding to criticisms made by journalists or political rivals, prompting the politician to express (usually brief) disagreement. In other words, while politicians were willing to contest what the IFS said, they were much less likely to contest the IFS's authority to say it. This is an important distinction. Conflict was mostly limited to the politician either reasserting a challenged claim, or expressing brief disagreement with the IFS analysis being put to them. The journalist would then continue to use the IFS's views, with no discussion of why they could be incorrect or whether the IFS should be used as an authority in this way.

Only one interview went beyond brief disagreement and involved criticism of how the IFS's analyses were produced. This came from SNP leader Nicola Sturgeon when she responded to the use of IFS reports to challenge claims that the SNP could not end austerity in an independent Scotland. In an interview for Newsnight, Sturgeon told BBC political reporter Laura Kuenssberg: "If you are referring to the IFS report today when you talk about independent assessment, I don't accept much of the underpinning assumptions made in the IFS report" before going on to give reasons why "the IFS have got it wrong about the SNP plans." Sturgeon was willing to go further than all the other politicians in mainstream broadcast news during the 2015 campaign because she wanted to argue that the IFS was aligned with the Westminster elite in London. Despite arguing that the IFS's criticism was based on false assumptions, however, Sturgeon stopped short of overtly questioning Kuenssberg's construction of the think tank as providing an "independent assessment" and during the same interview she even accepted what she termed the IFS's "praise" for the SNP. ${ }^{12}$ 


\section{Conclusion}

During the 2015 U.K. general election campaign, whatever the IFS said was consistently treated as fact. While contested authority signaling did occur, it was ineffective for challenging the role of the IFS as a primary definer, especially in the face of the overwhelming weight of assumed and overt authority signaling we identified. Given these findings, our concern is that the "dance" between political elites and journalists, in a field of news that is crucially important, becomes a superficial and ritualized exchange.

During the 2015 campaign, assumed authority signaling was the most prevalent way in which the IFS was constructed by broadcasters. When assumed authority signaling was used the IFS's status as an independent economic expert was neither questioned nor overtly established. As a result, the IFS's role as the ultimate primary definer for economic policy news became entrenched in reporting; a matter of fact external to both journalists and politicians.

Repeatedly constructed as an expert source in framing, focusing, realizing and closing, the IFS became a key part of the mediated reflexivity that now typifies broadcast political coverage (Davis, 2009). The upside is that constructing the authority of the IFS creates space for journalists to routinely weigh up politicians' claims, while maintaining distance and impartiality. The downside is that this process renders the IFS's views virtually incontestable. If impartiality involves journalism giving public voice to a diverse range of policy perspectives, UK journalists are falling short during elections.

We also unearthed journalists' frequent use of the term "belief" and its derivatives. This terminology reveals not only the broadcasters' own faith in the infallibility of the IFS, but also places politicians in a position where they are unable to successfully contest the IFS's authority. Whilst technically able to cast doubt on statistics from the IFS, doing so 
becomes a futile exercise for politicians because journalists respond with the think tank's supposed infallibility. Given its infallible status, politicians also naturally seek to use the IFS to support their own arguments. When both politicians and journalists use language that constructs the IFS as an assumed authority external to themselves, the true winner is the IFS itself. The repetitive and formulaic use of assumed authority signaling means this discursive move is not always obvious.

Repeatedly constructing the IFS as an almost unchallenged authority has consequences for economic policy debates. The over-reliance on the IFS as an expert source comes at the expense of other voices, narrowing and limiting scope for debate. We have shown that the think tank is used as a source to provide a "check" on politicians, but this does not provide balance when the views of the IFS are so rarely contested. As we have argued, the persistent use of assumed authority signaling means that those whose arguments were on occasion juxtaposed with the IFS's - politicians — did not have a genuine opportunity to contest the think tank's authority, and in any case politicians had strong incentives for not doing so, for fear of appearing marginal to the common sense of economic debate.

Finally, where overt authority signaling was used, the IFS was constructed as possessing category entitlements and was contrasted with politicians, who were constructed as lacking those entitlements. The dominant assumption is that politicians, as partisan representatives, cannot be trusted to present information or arguments on economic policy. While it is obviously important that party policy is exposed to critique during election campaigns, the danger here is that, due to the authority signaling incentive structure we identify, legitimate and representative party views on economic policy become marginalized by the views of a single think tank and trust in politicians is likely to be eroded in the process. 


\section{References}

Albæk E (2011) The Interaction Between Experts and Journalists in News Journalism. Journalism, 12(3): 335-348.

Anstead, N and Chadwick, A (2018) A Primary Definer Online: The Construction and Propagation of a Think Tank's Authority on Social Media. Media, Culture \& Society 40(2): 246-266.

Bennett WL (1990) Toward a Theory of Press-State Relations. Journal of Communication 40(2): 103-125.

Carlson M (2017) Journalistic Authority: Legitimating News in the Digital Age New York: Columbia University Press.

Cockett R (1995) Thinking the Unthinkable: Think-Tanks and the Economic CounterRevolution 1931-1983. London: HarperCollins.

Craig G (2016) Performing Politics: Media Interviews, Debates, and Press Conferences. Cambridge: Polity.

Cushion, S (2015) News and Politics: the Rise of Live and Interpretive Journalism. Abingdon: Routledge.

Cushion, S and Thomas, R (2017) From Quantitative Precision to Qualitative Judgements: Professional Perspectives About the Impartiality of Television News During the 2015 UK General Election. Journalism https://doi.org/10.1177/1464884916685909

Cushion, S, Kilby, A, Thomas, R, Morani, M and Sambrook, R (2016) Newspapers, Impartiality and Television News: Intermedia Agenda-Setting During the 2015 UK General Election Campaign. Journalism Studies. https://doi.org/10.1080/1461670X.2016.1171163 
Cushion S, Lewis J and Callaghan R (2016) Data Journalism, Impartiality and Statistical Claims: Towards More Independent Scrutiny in News Reporting. Journalism Practice. http://dx.doi.org/10.1080/17512786.2016.1256789

Davis A (2009) Journalist-Source Relations, Mediated Reflexivity and the Politics of Politics. Journalism Studies 10(2): 204-219.

Downey J and Toynbee J (2016) Ideology: Towards Renewal of a Critical Concept. Media, Culture \& Society 38(8): 1261-1271.

Edelman M (1988) Constructing the Political Spectacle. London: University of Chicago Press.

Ekström M (2002) Epistemologies of TV Journalism. Journalism 3(3): 259-282.

Franklin B and Carlson M (eds) (2010) Journalists, Sources, and Credibility: New Perspectives. Abingdon: Routledge.

Gans HJ (1979) Deciding What's News: A Study of CBS Evening News, NBC Nightly News, Newsweek and Time. New York: Random House.

Goffman E (1981) Forms of Talk. Oxford: Blackwell.

Hall S, Critcher C, Jefferson T, Clarke J and Roberts B (1978) Policing the Crisis: Mugging, the State, and Law And Order. London: Macmillan.

Hartley, J (1982) Understanding News. London: Routledge.

Herbst S (2003) Political Authority in a Mediated Age. Theory and Society 32(4): 481-503.

Latour B and Woolgar S (1986) Laboratory Life: The Construction of Scientific Facts. Princeton: Princeton University Press.

Lewis, J. and Cushion, S. (2017) Think Tanks, Television News and Impartiality: The Ideological Balance of Sources in BBC Programming. Journalism Studies https://doi.org/10.1080/1461670X.2017.1389295 
Potter J (1996) Representing Reality: Discourse, Rhetoric and Social Construction. London: Sage.

Reich Z (2012) Journalism as Bipolar Interactional Expertise. Communication Theory 22(4): $339-358$.

Rich A and Weaver RK (2000) Think Tanks and U.S. Media. International Journal of Press/Politics 5(4): 81-103.

Schlesinger P (2009) Creativity and the Experts: New Labour, Think Tanks, and the Policy Process. International Journal of Press/Politics 14 (1): 3-20.

Schudson M and Anderson C (2009) Objectivity, Professionalism and Truth-Seeking in Journalism. In: Wahl-Jorgensen K and Hanitzsch T (eds) The Handbook of Journalism Studies. New York: Routledge, 88-102.

Stone D (1996) Capturing the Political Imagination: Think Tanks and the Policy Process. London: Frank Cass.

Tuchman G (1978) Making News: A Study in the Construction of Reality. New York: Free Press.

Zelizer B (1990) Achieving Journalistic Authority Through Narrative. Critical Studies in Mass Communication 7(4): 366-376. 
Table 1. Broadcast News Programs Selected for Analysis

\begin{tabular}{|c|c|c|c|c|c|c|}
\hline Channel & Program & $\begin{array}{l}\text { Episodes } \\
\text { analyzed } \\
\text { (N) }\end{array}$ & $\begin{array}{c}\text { Segments } \\
\text { featuring } \\
\text { IFS } \\
\text { (N) }\end{array}$ & $\begin{array}{c}\text { Total } \\
\text { duration of } \\
\text { episodes } \\
\text { analyzed } \\
\text { (hours) }\end{array}$ & $\begin{array}{l}\text { Total duration } \\
\text { of segments } \\
\text { featuring IFS } \\
\text { (hours) (and as } \\
\text { a percentage of } \\
\text { total episode } \\
\text { hours) }\end{array}$ & $\begin{array}{c}\text { Mean } \\
\text { duration of } \\
\text { each segment } \\
\text { featuring } \\
\text { IFS } \\
\text { (minutes) }\end{array}$ \\
\hline $\mathrm{BBC} 1$ & News at Ten & 27 & 9 & 12.9 & $0.56(4.34 \%)$ & 3.71 \\
\hline $\mathrm{BBC} 2$ & Newsnight & 26 & 4 & 21.4 & $0.73(3.41 \%)$ & 10.94 \\
\hline Channel 4 & Channel 4 News & 38 & 8 & 26.6 & $0.79(2.97 \%)$ & 5.92 \\
\hline Channel 5 & 5 News Tonight & 24 & 4 & 10.1 & $0.39(3.86 \%)$ & 5.88 \\
\hline ITV & $\begin{array}{l}\text { ITV News at Ten } \\
\text { \& ITV News } \\
\text { Tonight }\end{array}$ & 27 & 4 & 16.7 & $0.16(0.96 \%)$ & 2.4 \\
\hline BBC Radio 4 & Today & 27 & 17 & 45.5 & $2.04(4.48 \%)$ & 7.18 \\
\hline Mean & & & & & & 6.08 \\
\hline Totals & & 169 & 46 & 133.2 & $4.67(3.50 \%)$ & \\
\hline
\end{tabular}

Figure 1. Overview of authority signaling by news anchors and reporters in broadcast segments featuring the IFS (counts and percentages) 


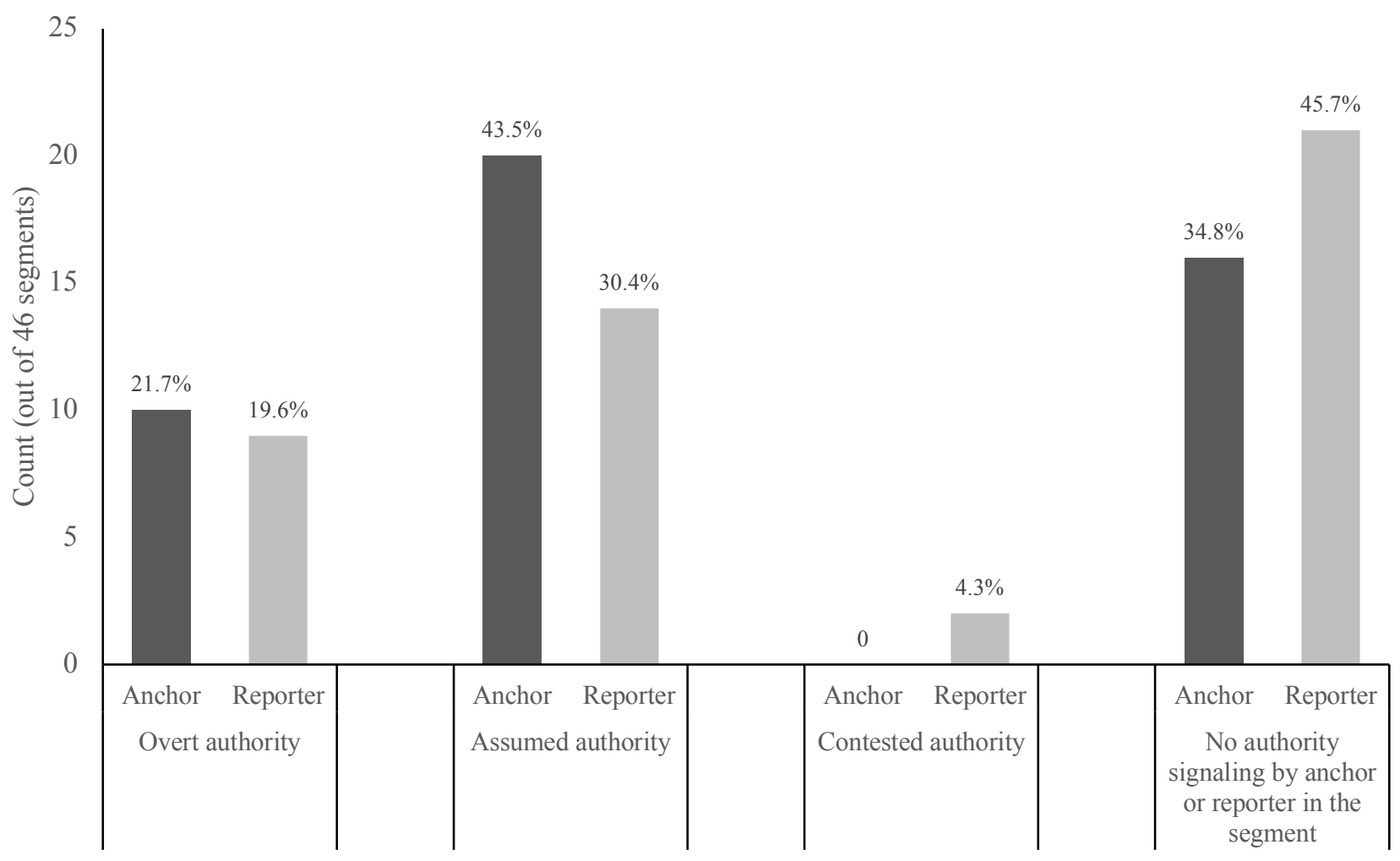


Figure 2. Overview of authority signaling of the IFS by political party sources

7

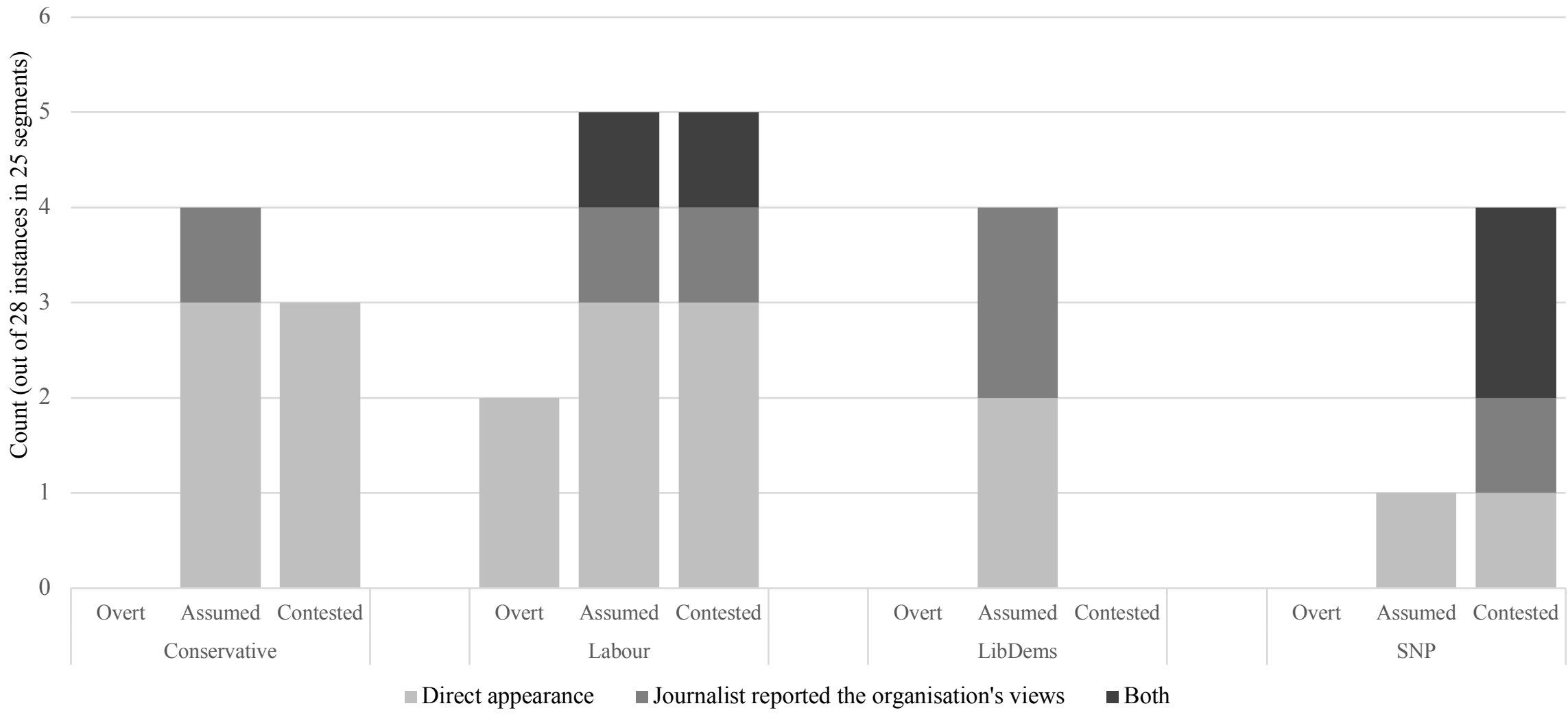

Note: 28 instances of organizations authority signaling in the 25 segments that featured at least one organization signaling the IFS's authority. 


\section{Notes}

${ }^{1}$ We excluded Saturday editions of Today for efficiency's sake: these feature less campaign news.

${ }^{2}$ Inter-coder reliability ranged from .72 to 1 exceeding the acceptable minimum of 0.667 . Our pilot and final coding frames, reliability tests, and links to online video of the programs are available for download in our online data and method file at http://files.andrewchadwick.com/journalism2018/data and method file.zip

${ }^{3} 5$ News Tonight, May 6, 2015.

${ }^{4} 5$ News Tonight, April 23, 2015.

${ }^{5}$ Today. April 7, 2015.

${ }^{6}$ Channel 4 News, March 30, 2015.

${ }^{7}$ BBC News at Ten, April 10, 2015; BBC News at Ten, April 132015.

${ }^{8}$ BBC News at Ten, April 23, 2015.

${ }^{9}$ ITV News at Ten, April 23, 2015.

${ }^{10}$ Newsnight, March 30, 2015.

${ }^{11}$ Today, April 9, 2015.

${ }^{12}$ Newsnight, April 23, 2015. 